\title{
"LA CASA AYMARA EN ENQUELGA" DEL DR. VÁCLAV ŠOLC. COMENTARIO CRÍTICO DE UN TEMPRANO ESTUDIO ETNOGRÁFICO ANDINO EN CHILE
}

\author{
Hans Gundermann Kröll ${ }^{1}$
}

El estudio de la casa aymara en Enquelga es uno de los pocos trabajos publicados por el Dr. Šolc como resultado de sus estudios en el norte de Chile. El autor, como sabemos, fue miembro importante de una misión checo alemana de etnólogos ${ }^{1}$ que en Chile efectuaron campañas de investigación desde 1966 en adelante, hasta el momento mismo del quiebre democrático en 1973. Las estadías en Enquelga corresponden a un momento intermedio de actividad; según declara, pasó algunos meses en el lugar durante 1968 y 1969. Esa escasa producción sobre el norte indígena favoreció que en la producción intelectual de este grupo fueran más conocidos los estudios del Dr. Milan Stuchlik sobre los mapuches del centro sur del país (Stuchlik 1974, 1999 [1976]); como se recordará, este último fue otro etnólogo checo adscrito al grupo ${ }^{2}$.

No obstante lo anterior, las indagaciones en el norte de Chile tienen una doble importancia. Como el mismo autor advierte "toda esta región es muy poco conocida e investigada" (Šolc 1975:111); etnológicamente y en aquel entonces, debemos precisar. En efecto, sólo el estudio de la localidad atacameña de Peine realizado por Grete Mostny (1951) casi dos décadas antes y respecto de otro grupo étnico, puede considerarse un miembro de la familia de estudios que la "Casa aymara..." inaugurara en la zona andina septentrional. Habrá luego que especificar en qué consiste esa familia de estudios. Las regiones interiores de Arica y Tarapacá no carecen de pesquisas sistemáticas; recuérdese los trabajos de Carlos Keller (1946) y Freddy Taberna (1968), con una inspiración que proviene de la economía y la geografía humana, y cuya motivación, cabe añadir, es integracionista en cuanto no está desprendida de las cuestiones del desarrollo local y, de manera más amplia, del desarrollo campesino y de regiones interiores que mediante inducción estatal se implementaba en el país como parte de las urgentes transformaciones modernizadoras que se demandaba a la agricultura nacional. Suscribiéndose el criterio de clasificación disciplinaria empleado, los trabajos realizados en la segunda mitad de la década de 1960 en Chapiquiña y Enquelga por los Dres. Šolc y Neumann inauguran los estudios antropológicos aymaras en $\mathrm{Chile}^{3}$.

$Y$ ya que de clasificaciones sociales hablamos, hay un segundo aspecto relacionado respecto del cual la "Casa aymara..." llama a un comentario. En el texto se habla de "indios", pero como el propio título lo expresa, específicamente de "aymaras". Se realiza una etnología de los hogares de un remoto poblado de "indios aymaras" y esto constituye una novedad ${ }^{4}$. Veamos por qué puede considerarse así. No era desconocido en algunas agencias estatales y en los gobiernos provinciales y departamentales que en las zonas interiores andinas vivían "indios" o gentes con ancestros "indios", no obstante que muchos de ellos, especialmente los residentes en los principales valles y quebradas de la zona, claramente no se apreciaban como tales. Tendían a argumentar, más bien, que sus antecesores eran hispanos o en cualquier caso, peruanos (significando así su permanencia anterior a la anexión del territorio por parte de Chile) y reservando la condición de "indios" para aquellos que, como los de Enquelga, más distantes y aislados respecto de los centros poblados de la costa y el desierto, mantenían la lengua, vestían y practicaban costumbres de "indios". En el contexto regional la categoría social de los "indios" quedaba en lo sustancial cubierta por una posición social subordinada, carencia y negatividad (atrasados, incivilizados, poco integrados, pobres, incultos, primitivos, etc.). La cultura, lo que para un etnólogo hace posible hablar de "aymara", es aquí un signo de confirmación de la ausencia que los define. La condición de "indio" no representa un valor en sí mismo.

Un etnólogo partícipe de las tradiciones de pensamiento antropológico del centro y norte de Europa arranca de un principio distinto: el de la universalidad y la igualdad básica de las diferentes

Instituto de Investigaciones Arqueológicas y Museo (IIAM), Universidad Católica del Norte en San Pedro de Atacama. hgunder@ucn.cl 
culturas. Los "indios" pueden entonces no corresponder sólo a negatividad, sino que también participan de "cultura"; en este caso la aymara". Están así envestidos de una dignidad constitutiva ${ }^{6}$. La innovación en los estudios regionales de los "indios" del extremo norte de Chile resulta ser entonces doble: se elabora conocimiento etnológico y ello se realiza según un enfoque antropológico que, cuando observa, reconoce culturas. Por lo demás, la política indigenista está por ese entonces cambiando, lo que da un contexto favorable a un enfoque de este tipo. A principios de la década de 1960, por primera vez desde el Estado chileno la política hacia los indígenas, antes exclusivamente dirigida a la protección-integración de los mapuches a la sociedad nacional, se abre a un tímido reconocimiento y las primeras acciones hacia los otros pueblos nativos del país, entre ellos los aymaras y atacameños. En el extremo norte del área se implementa por esos años el Plan Andino de Desarrollo, un programa subregional de UNESCO ejecutado en la zona por la Junta de Adelanto de Arica.

¿Qué tipo de etnología es esta? Tracemos algunas características a partir de las pistas que nos da la "Casa aymara en Enquelga". Podemos definirla como culturalista, internalista e históricamente continuista; epistemológicamente objetivista y metodológicamente etnográfica. Fundamentemos este conjunto de juicios. Culturalista, primero, en cuanto se asume estar en presencia de un grupo local miembro de una cultura; es decir, una unidad amplia integrada en unidades locales de población, con tradición y formas de vida específicas. Teniendo esta perspectiva indudables ventajas respecto de las visiones elitistas de la cultura, no deja tampoco de presentar otras dificultades: su tendencia a la descripción por inventarización y fijación de rasgos $\mathrm{y}$, por lo tanto, a dar poco margen a la heterogeneidad y a la dinámica sociocultural. No es la única dificultad; otra notoria es la virtual ceguera ante las diferencias, ya no culturales, sino sociales. $\mathrm{La}$ desigualdad social, un dato importante de la causa, no tiene aquí algún lugar reconocible.

Lo anterior trae a colación los problemas del internalismo (Thompson (1993:422-423), falacia que denota la cuasi total ausencia de preocupación por las condiciones sociohistóricas y los vínculos estructurales que estas poblaciones indígenas guardan con las regiones, Estados nacionales y sistemas económicos amplios a los cuales están adscritos o relacionados. El autor percibe con perfecta claridad el fenómeno de la migración de los campesinos altoandinos hacia los valles precordilleranos occidentales, relevando a los antiguos residentes de esas zonas que ya habían empezado a migrar a los centros urbanos costeros (Šolc 1975:112). Estas migraciones, lo sabemos ahora, darán origen a profundas transformaciones sociales (Gundermann 2001). Todo pasa entonces como si la sociedad y la cultura indígenas resultaran autoevidentes y autoexplicantes a la observación.

Continuista, también, en la medida que la visión de lo "aymara", tributaria de un enfoque culturalista, es la de una entidad colectiva persistente al paso de los siglos. Dirá que los indígenas del "Altiplano chileno" pertenecen a la cultura más amplia aymara, cuya formación debe retrotraerse al menos hasta la "cultura elevada" Titicaca-Desaguadero (de agricultores y pastores) (Šolc 1975:111). Testimonian esa persistencia numerosas prácticas y objetos. Cita el ejemplo de las pequeñas cavidades de las casas aymaras llamadas phutu, que se encuentran a lo menos desde Tiwanaku (Šolc 1975:123-124). En la medida que se tengan filiaciones culturales se tendrán también filiaciones sociales; bien sabemos de los insalvables problemas implicados en esta asimilación. Por lo demás, aun en el campo de las prácticas y las materialidades, la determinación de los casos es recurrentemente selectiva: las pruebas terminan normalmente confirmando la tesis. No queda espacio para las transformaciones, a veces muy profundas, que en más de una ocasión han sufrido estas poblaciones. Piénsese nada más en los brutales cambios de los últimos siglos, redefiniendo a veces radicalmente su condición social y, también, cultural. Son conocidos los casos andinos de abandono de la lengua aymara por el quechua y, con ello, podemos decir, de una cultura, en tanto que compartamos la idea de que una lengua es sinónimo de una cultura. Es el caso, por ejemplo, de toda la región Lípez (en el sur occidente de Bolivia).

La del Dr. Šolc es todavía una forma de etnografía centrada en el caso, en la comunidad indígena, en los escenarios locales. Se trata de establecer un registro minucioso y prolijo, realizado de manera competente, objetiva y confiable de todo aquello que puede caracterizar una cultura india. En su estudio de los aymaras de las islas del Titicaca los capítulos ilustran bien qué es para él describir una cultura: se habla de la región, la población, la alimentación, el tratamiento de los alimentos, la habitación, el vestuario, las manufacturas, el comercio y las 
comunicaciones, el ciclo de vida y la recreación (Šolc 1969). Desde la formación recibida participa así de una forma de construcción el objeto de investigación y de investigar que por aquel entonces (segunda mitad de la década de 1960) se había ya instalado y expandido por doquier en la antropología latinoamericana; en parte por procesos de formación anteriores, en parte por la influencia y hegemonía que adquirían las universidades norteamericanas y sus estudiosos (Kearney 1996).

¿Qué es lo que al final de cuentas nos queda? Junto a Lotte Wiesner de la Sociedad Antropológica de Chile, nos legó una prolija descripción de la vivienda aymara, su construcción y la forma de habitarla, junto con una clara morfología de un poblado andino; claro está, menos antiguo de lo que él creía y menos tradicional (no influido externamente) de lo que suponía. Aunque nos parezca hoy un tanto anacrónico, participa de una tradición antropológica venerable: la que entendía su misión como la descripción cuidadosa de la cultura de los pueblos no occidentales (las costumbres, las tradiciones, las tecnologías, los objetos). Entendía su trabajo así y lo realizó bien; podríamos decir hoy que es un ejemplo no de método, pero sí de metodicidad.

Calamarca, Ayllo Solcor, 09/02/2004.

\section{Referencias Citadas}

Gundermann, $\mathrm{H}$.

2001 Procesos regionales y poblaciones indígenas en el norte de Chile. Un esquema de análisis con base en la continuidad y los cambios de la comunidad andina. Estudios Atacameños 21:89-112.

Kearney, M.

1996 Reconceptualizing the Peasantry. Anthropology in Global Perspective. Westview Press, Estados Unidos.

Keller, C.

1946 El Departamento de Arica. Ministerio de Economía y Comercio, Santiago.

Mostny, G.

1954 Peine, un pueblo atacameño. Publicación $N^{\circ} 4$, Instituto de Geografía, Universidad de Chile, Santiago.

Šolc, V.

1969 Los Aymaras de las Islas del Titicaca. Instituto Indigenista Interamericano, Serie Antropología Social $\mathrm{N}^{\circ}$ 12, México.
1975 Casa aymara en Enquelga. Annals of Náprstkovo Muzeum 8:111-146.

Stuchlik, M.

1974 Rasgos de la Sociedad Mapuche Contemporánea. Universidad Católica de Chile, Santiago.

1999 [1976] La Vida en Mediería. Mecanismos de Reclutamiento Social de los Mapuches. Soles Ediciones, Santiago [1ra. Edición en inglés de 1976 bajo el título de Life on a Half Share].

Taberna, $\mathrm{F}$

1968 Los Andes y el Altiplano Tarapaqueño. Tesis de Lic. en Historia y Geografía, Universidad de Chile, Santiago.

Thompson, J.

1993 Ideología y Cultura Moderna. Teoría Crítica Social en la Era de la Comunicación de Masas. UAM-Xochimilco, México (1ra. Edición en inglés de 1990).

Notas

1 El Museo Náprstek de Praga en la entonces Checoslovaquia y el Museo Estatal de Etnología de Dresden, en la ex República Democrática Alemana.

2 Que además integraba la Dra. Olga Pichová Kandertová del Museo Náprstek, como nos informa el Dr. Šolc.

3 Para la etnología chilena de la primera mitad del siglo XX, misma que había alcanzado cierto desarrollo a partir de la influencia de académicos alemanes y austríacos (el Dr. Max Uhle, el Dr. Martin Gusinde, más tarde la Dra. Grete Mostny), así como de epígonos chilenos (Latcham, Montandón, entre otros), los pueblos indígenas del país eran los mapuches y también los fueguinos. Las poblaciones indígenas andinas eran poco conocidas, se les atribuía una exigua población, permanecían en calidad de supervivientes de profundos cambios culturales acaecidos en tiempos coloniales y republicanos y, además, se encontraban prontos a integrarse y desaparecer como culturas diferenciadas.

4 Para ser más precisos, la identificación de los "indios" del norte del país como aymaras, como integrantes de una cultura más amplia, fue durante gran parte del siglo XX una atribución reservada a algunos estudiosos y profesionales informados desde la literatura antropológica. En la región y entre los propios indígenas no existió sino hasta poco más de una década una identificación generalizada como pueblo "aymara". Con Šolc encontramos un temprano estudio etnológico informado por una visión de estos indígenas como "cultura aymara".

5 Que por cierto trasciende las fronteras nacionales. Los aymaras de Chile son concebidos como parte de los aymaras de Bolivia y Perú. Se recordará que el Dr. Šolc había previamente estudiado los aymaras de las islas del Titicaca boliviano durante 1963 y publicado los resultados en México el año 1969 (Šolc 1969).

6 ¿Cómo se integra aquí condición de clase, relaciones de poder, posición de subordinación? El trabajo no nos da luces suficientes al respecto, a pesar de representar cuestiones de suyo evidentes. 